\title{
BACKGROUND
}

- The co-stimulatory CD40-CD40L axis is a major driver of atherosclerosis.

- Both platelets and T cells express express CD40L, but its cellspecific role and impact on atherosclerosis remains elusive.

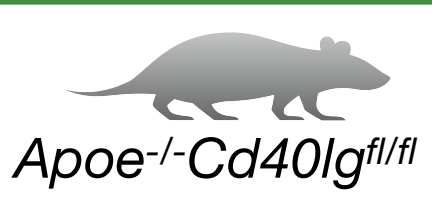

Apoe- $-\mathrm{Cd} 40 \mathrm{Olg}$

Pf 4 Cretg

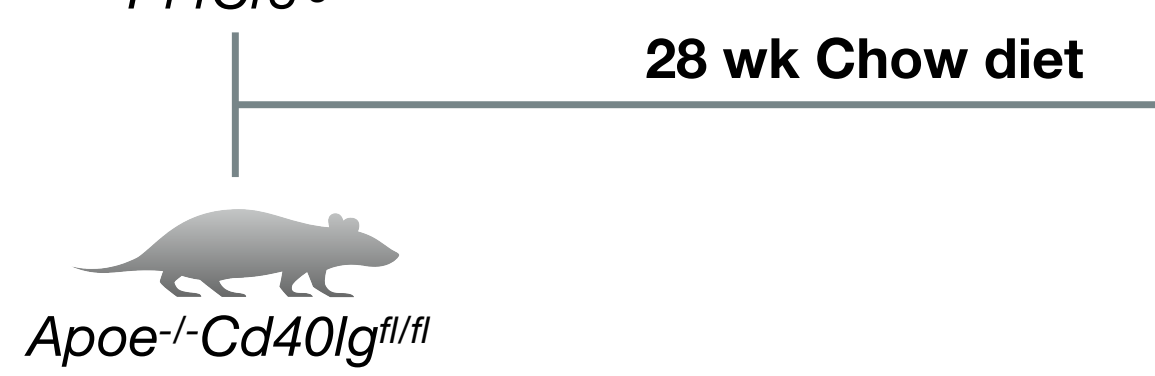

Apoe- - Cd40lgfl/fl

Cd4Cretg

WT $\square$ Pf4Cre

$\stackrel{1}{1}$

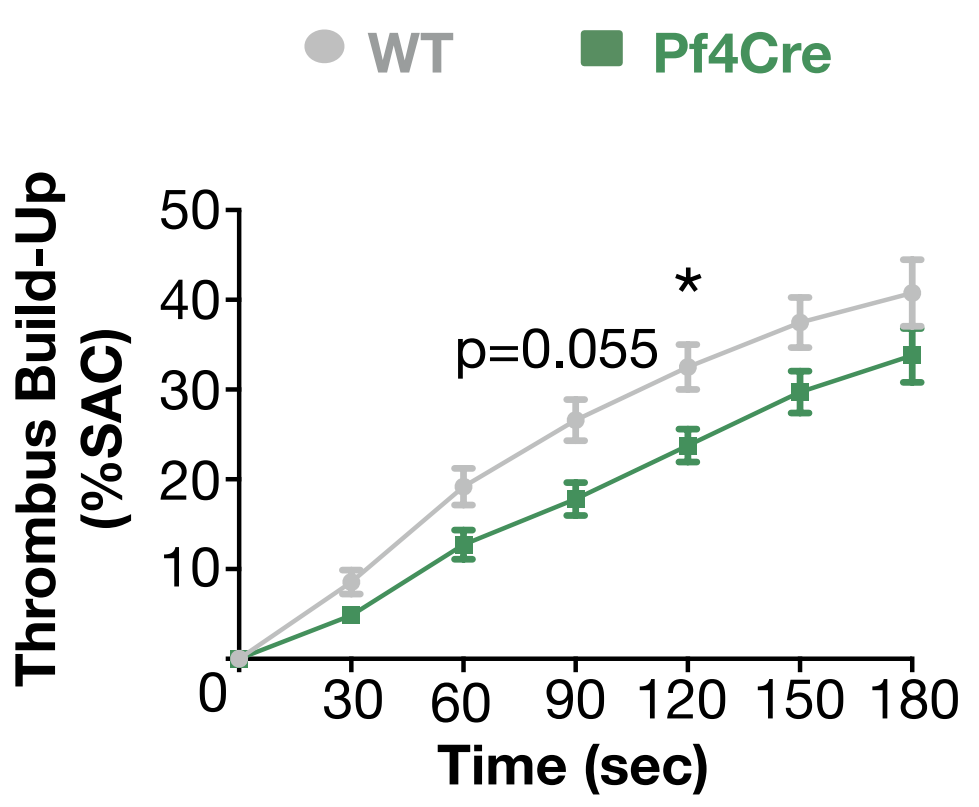

\section{EXPERIMENTAL PLAN}

\section{PHENOTYPING CD4OL-DEFICIENT PLATELETS}
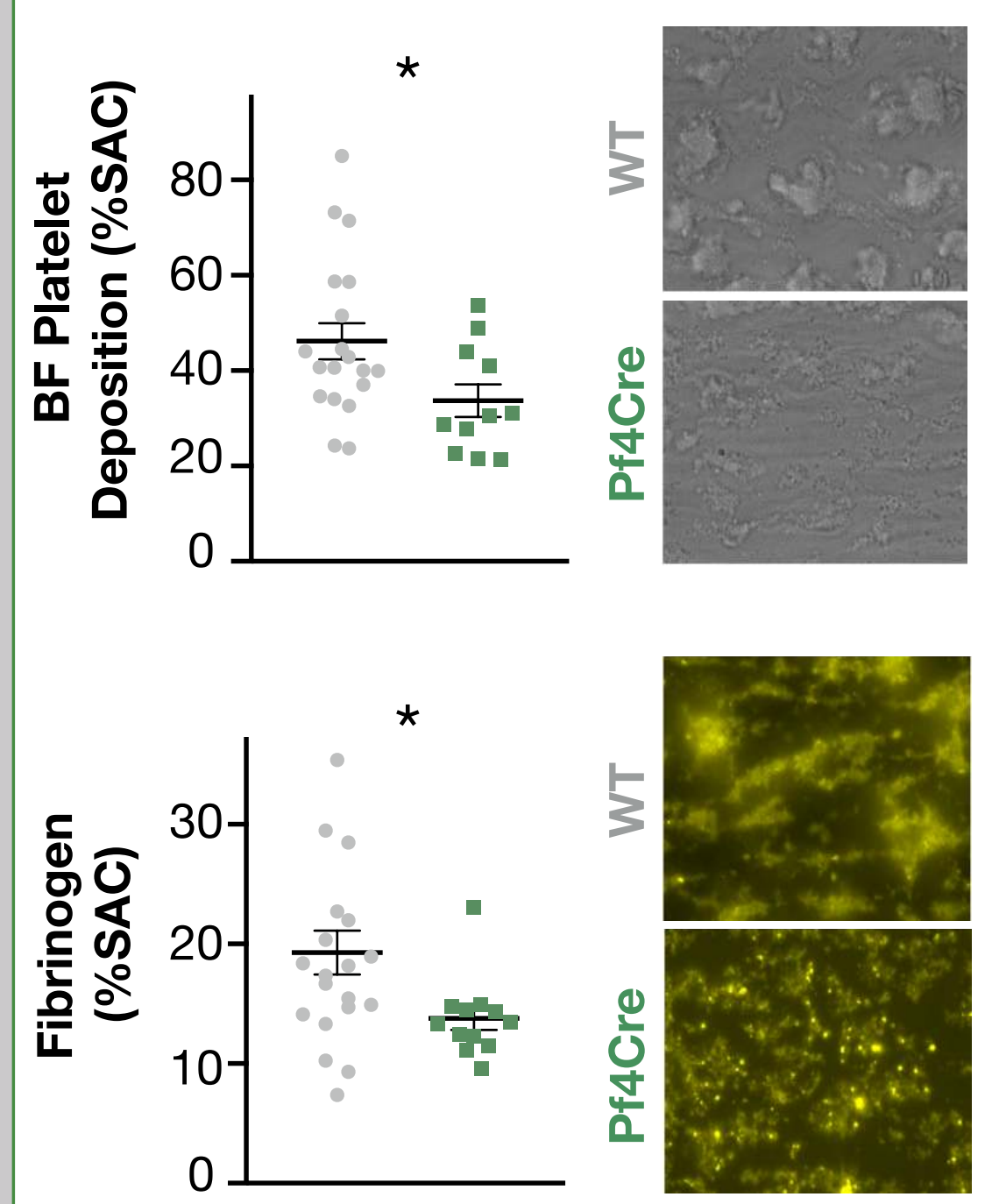

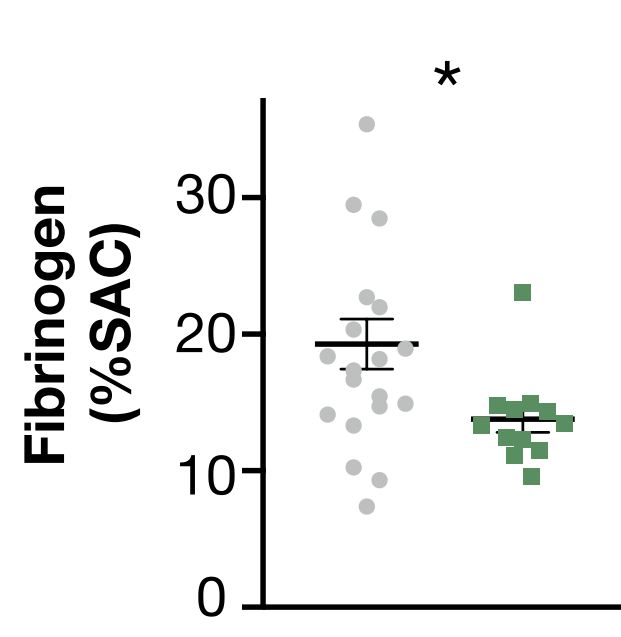

T-cell Deficiency Plaque Measurement

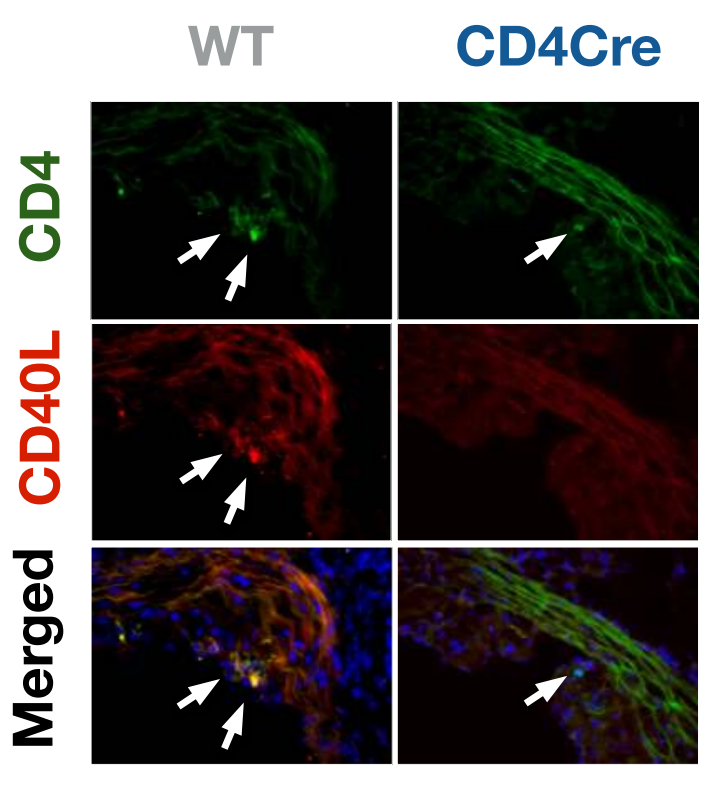

Platelet Deficiency Plaque Measurement, Platelet Phenotyping,

Considering its role in thrombosis, we continued to phenotype CD40Ldeficient platelets via whole blood micro-spot perfusions.

- We observed decreases in platelet deposition (top) as well as fibrinogen content (bottom) in CD40LAtherothrombosis
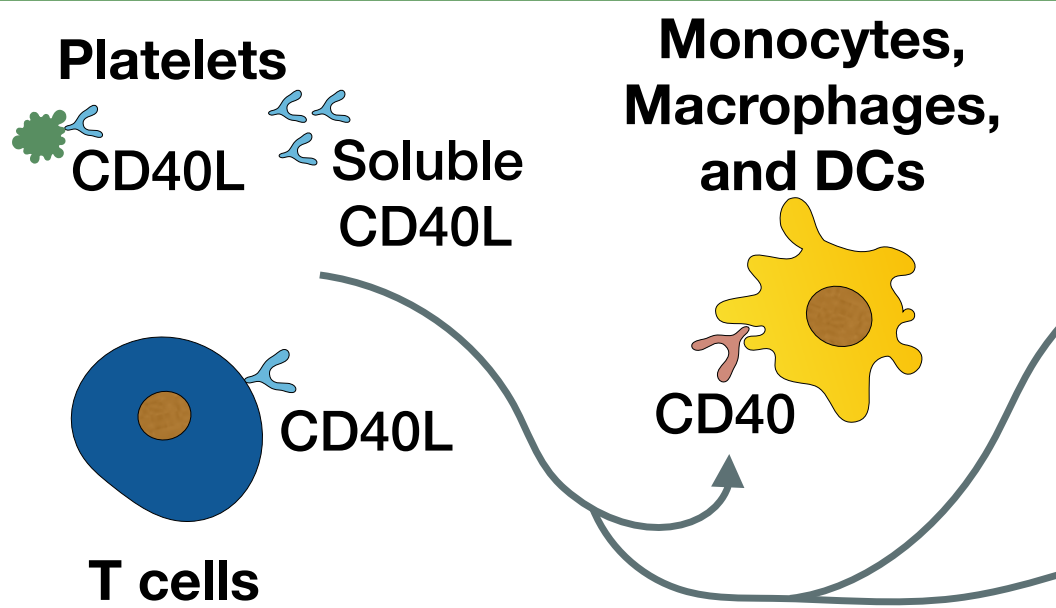

Smooth Muscle Cells

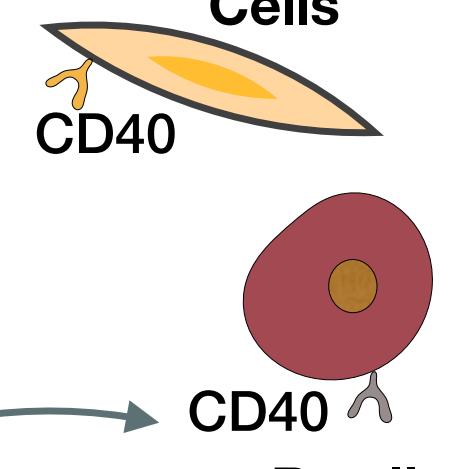

\section{CELL-SPECIFIC DIFFERENCES IN PLAQUE BURDEN}

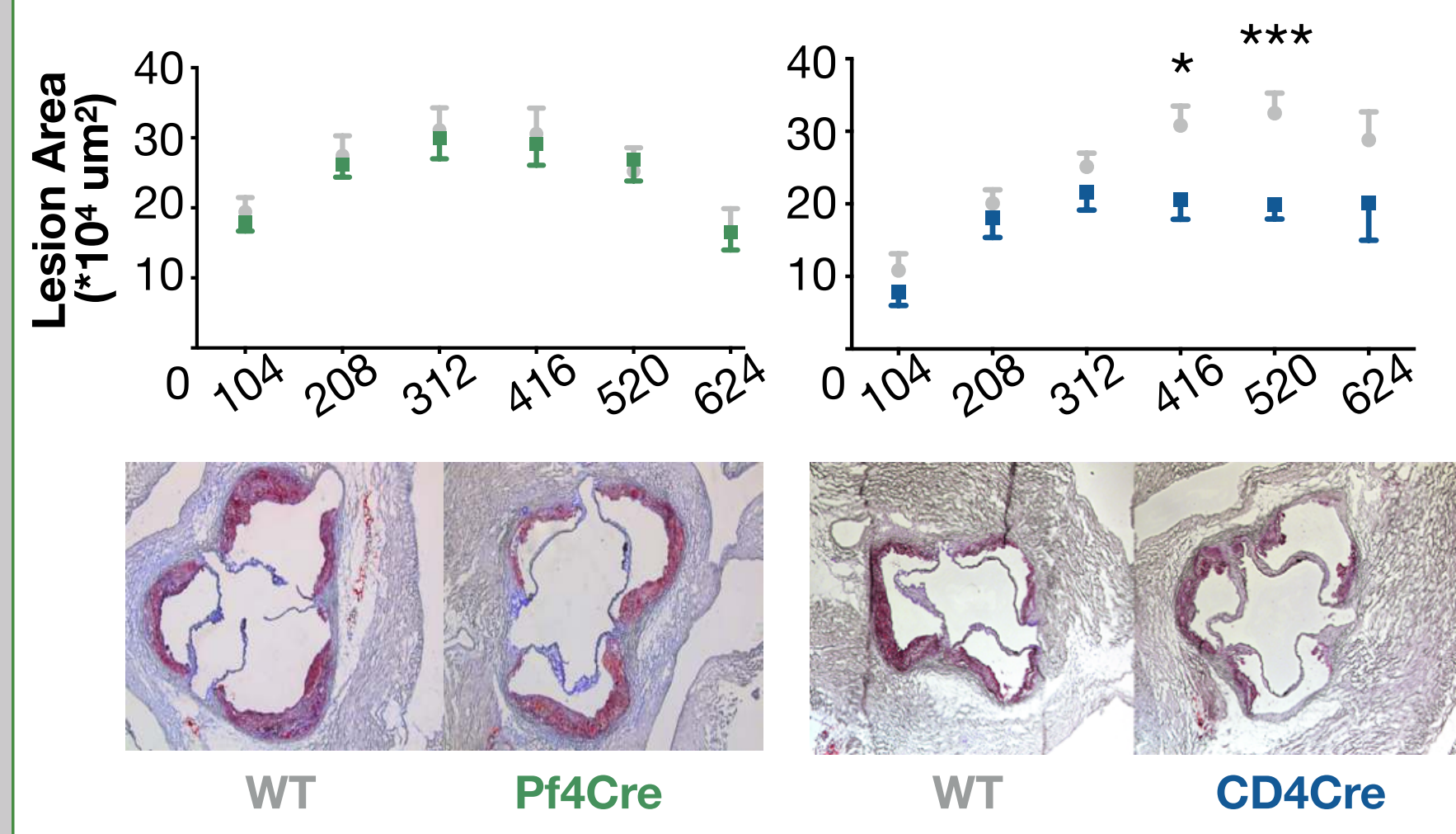

- Oil-red $\mathbf{O}$ analysis of aortic root plaques revealed a stark difference in atherosclerotic potential between platelet CD4OL (left), where deficiency did not reduce plaque burden, versus Tcell CD40L (right), where deficiency attenuated atherosclerosis.

PLATELET CD4OL IN ATHEROTHROMBOSIS

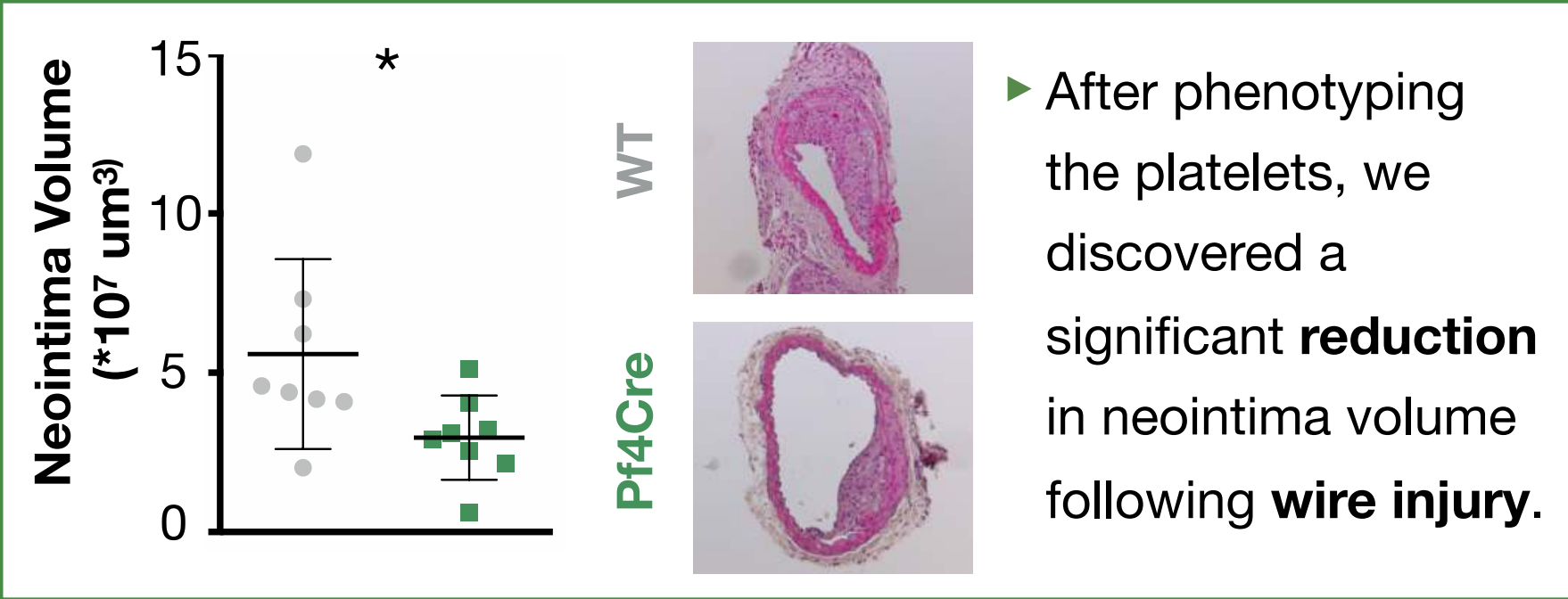

\section{CONCLUSIONS} deficient platelets.

- Our data demonstrate differing roles for platelet and T-cell CD40L in atherosclerosis.

- Specifically, T-cell CD40L mediates atherogenesis while platelet CD40L plays crucial roles in thrombus formation as well as neointima growth following injury suggesting platelet CD40L plays a key role in atherothrombosis. 